\title{
Evaluating the simulation of radiation dose reduction in a digital breast tomosynthesis system featuring an amorphous silicon (a-Si) detector Avaliação da simulação de redução da dose de radiação em um sistema de tomossíntese digital mamária com detector silício amorfo (a-Si)
}

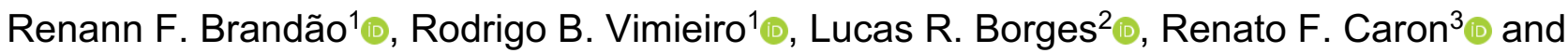 \\ Marcelo A. C. Vieira ${ }^{4}$
}

${ }^{1}$ Department of Electrical and Computer Engineering, University of São Paulo, São Carlos, Brazil ${ }^{2}$ Department of Medical Clinic, University of São Paulo, Ribeirão Preto, Brazil ${ }^{3}$ Barretos Cancer Hospital, Pio XII Foundation, Barretos, Brazil

\begin{abstract}
Resumo
A validação de muitos métodos de otimização de dose de radiação em imagens de raio $X$ necessita de uma grande quantidade de imagens clínicas com diferentes relações de sinal-ruído. Esses dados são normalmente gerados através de simulações computacionais. Para alcançar esse objetivo, nosso grupo desenvolveu um método de simulação de redução de dose para tomossíntese digital mamária. Neste trabalho apresentado anteriormente, os testes foram feitos em um equipamento com detector de amorfo selênio, com correlação mínima entre os pixels. Neste trabalho proposto, busca-se avaliar o desempenho da simulação em sistemas de amorfo-silício. As características do sinal e do ruído nas imagens reais e simuladas foram medidas através da relação sinal ruído (SNR) e do espetro de potência do ruído (NNPS). Para medir a performance do método, o erro relativo médio entre as imagens reais e simuladas foi estimado. Os resultados apontam um erro menor que $2,5 \%$ entre as imagens simuladas e reais em termos de SNR. A influência da correlação do ruído considerado no método foi verificada através do NNPS. Os testes apontaram um erro de até $55 \%$ entre as imagens reais e simuladas, em termos de NNPS, sem o kernel de correlação enquanto que o erro considerando a correlação foi em torno de $5,5 \%$. Portanto, os resultados mostram que a correlação do ruído é um fator importante a ser considerado durante a simulação de sistemas amorfo-silício.
\end{abstract}

Palavras-chave: Tomossíntese digital mamária; redução da dose de radiação; ruído quântico; correlação do ruído; detector de raios $X$.

\begin{abstract}
The validation of many dose optimization methods in x-ray imaging requires clinical images from a range of signal-to-ratio regimes. This data is commonly generated through computer simulation. For this purpose, our group developed a method to simulate dose reduction for digital breast tomosynthesis. In the previous work, tests were performed in a system that features an amorphous selenium detector with minimal pixel correlation. In the current work, we evaluate the simulation performance in an amorphous silicon system, which yields a relevant pixel correlation. Signal and noise characteristics in real and simulated images were measured using the signal-to-noise ratio (SNR) and the normalized noise power spectrum (NNPS). The simulation method assessment was performed through the average relative error between simulated and real images. The SNR results point to an error of less than $2.5 \%$ between the images. The noise correlation influence was verified through the NNPS. The tests pointed to errors up to 55\% between the real and simulated images when the correlation kernel is not considered, whereas the error considering the correlation kernel was kept around $5.5 \%$. Therefore, the results show that the correlation kernel is a relevant factor to be considered when simulating amorphous silicon systems.
\end{abstract}

Keywords: Digital breast tomosynthesis; radiation dose reduction; quantum noise; noise correlation; $x$-ray detector.

\section{Introduction}

According to statistics from the National Cancer Institute (INCA), approximately 60,000 new breast cancer cases will be diagnosed in Brazil in $2019^{1}$. Screening is commonly advised to increase survival rates $^{2,3}$.

Digital breast tomosynthesis (DBT) is emerging as an important imaging tool for breast cancer screening. It creates a three-dimensional representation of the breast volume from a set of low-dose projections acquired within a limited angular range $\mathrm{e}^{4}$. This imaging modality minimizes tissue overlap inherent to conventional mammography ${ }^{5}$. As DBT relies on the acquisition of multiple projections, with approximately the same combined radiation dose as stated for $2 \mathrm{D}$ mammography, the relative noise is higher in each projection. A number of works investigated the relationship between radiation dose and diagnostic performance, showing that noise can negatively impact the detection of subtle signs of breast cancer, decreasing diagnostic accuracy ${ }^{6-12}$.

Studies on the optimization between radiation dose and image quality require image data from a range of noise levels. However, acquiring patient data at different dose levels would require repeated exposure of the same subject, and thus representing risks of induced cancer $^{13}$. One common approach to overcome this issue is to simulate dose reduction by 
adding the correct amount of noise to clinical data acquired at a standard radiation dose ${ }^{14-18}$.

Recently, our group presented a method to accurately simulate dose reduction in DBT images $^{19}$. The proposed method was built upon a noise model that considers the pixel offset, electronic noise, quantum noise, spatially-variant quantum gain and noise spatial correlation.

Although in ${ }^{19}$, the proposed algorithm considers the noise correlation, the validation was limited to a DBT system featuring an amorphous selenium (a-Se) detector, which is known to have approximately uncorrelated (white) noise. To the best of our knowledge, this algorithm has not been validated using a detector technology, which effectively produces noise with relevant correlation.

Thus, the objective of this work is to further evaluate the performance of the previously proposed simulation method when applied to a system with an amorphous silicon (a-Si) detector coupled with a thallium-doped cesium iodide (Csl:TI) scintillator. Such system is known to report noise with relevant spatial correlation, and thus this study is vital to support the simulation algorithm in scenarios where the correlation of noise cannot be neglected.

\section{Theoretical Background}

\subsection{Noise model}

In raw DBT projections, generally, two main sources of noise are considered relevant. The fluctuations on $\mathrm{x}$-ray photons flux, i.e. the quantum noise, is often modeled by a Poisson distribution, which is signaldependent. The electronic or thermal noise is commonly represented as a signal-independent Gaussian distribution. However, based on the Central Limit Theorem (CLT) it is feasible to model noise as a single Gaussian distribution, and thus:

$$
\begin{gathered}
y^{o}(i, j)=y(i, j)+\eta(i, j)+\tau, \\
\eta(i, j) \sim \mathcal{N}\{0, \sigma(y(i, j))\},
\end{gathered}
$$

where $i$ and $j$ are the 2D coordinates in the image, $y^{o}$ is the observed DBT raw projection, $y$ is the noise-free image, $\tau$ is the detector pixel offset, $\eta$ is a noise, $\mathcal{N}$ is a Gaussian distribution with zero mean and $\sigma$ is a function that models the noise standard deviation:

$$
\sigma(y(i, j))=\sqrt{\lambda(i, j) y(i, j)+\sigma_{E}^{2}}
$$

where $\lambda$ is the spatially-dependent quantum noise gain and $\sigma_{E}^{2}$ is the electronic noise variance. The signal-dependent component models the variance of the quantum noise while the signal-independent component models the variance of the electronic noise.

\subsection{Noise correlation}

The models presented in Equations 1, 2 and 3 do not explicitly consider pixel spatial correlation in the overall acquisition process. However, in DBT systems, noise correlation plays an important role ${ }^{19,20}$. It is often a consequence of the acquisition physics, the finite pixel size leading to pixel crosstalk and the indirect $x$-ray detection due to the scintillation process $^{21,22}$.

According to ${ }^{20}$, neglecting pixel correlation while performing image processing may affect the efficiency of the detection of subtle features like microcalcifications.

The detector crosstalk can be modeled with a kernel estimated using the noise power spectral density (PSD) ${ }^{19}$. Admitting the correlation, Equation 2 may be re-written to explicitly show spatial correlation:

$$
\eta_{c}(i, j) \sim \sigma(y(i, j))(K \circledast \mathrm{N}\{0,1\}),
$$

where $K$ is the noise correlation kernel in the spatial domain. The math symbol $\circledast$ stands for the convolution operation. This kernel was estimated as in Borges, et al ${ }^{19}$. Note that, to guarantee Equation 3, the $\mathrm{L} 2$ norm of $K$ must be unitary, i.e., $\|\mathrm{K}\|_{2}=1$.

\subsection{Dose reduction}

Following Borges, et al. ${ }^{19}$, dose reduction was simulated in five steps: linearization, quantum noise injection, signal scaling, electronic noise injection and offset injection.

In the first step, the standard dose image was linearized by subtracting the detector pixel offset. Next, quantum noise was injected to simulate a lower dose image. As the quantum noise is signaldependent, this process was performed using a variance-stabilizing transformation (VST), which converts the noise into signal-independent ${ }^{23}$. After noise injection at the VST range, the appropriate inverse transform was applied.

Next, the overall signal was scaled down by a factor of $\gamma(0<\gamma<1)$. The dose reduction factor is the ratio between the dose to be simulated and the dose of the input image. After scaling, the standard deviation of the electronic noise is below the expected by a factor of $\gamma$ and extra signal-independent noise is added to compensate.

The last step consists on adding the pixel offset, which was subtracted from the signal in the linearization step.

\section{Materials \& Methods}

Homogeneous raw projections were acquired using a poly methyl methacrylate (PMMA) uniform phantom (3cm thick), commonly used for flat-fielding calibration. These images were used to validate the simulation method due to its uniformity, allowing a good estimation of the signal and the noise properties.

All images were acquired using a General Electric (GE) Senographe Essential DBT system from the Barretos Cancer Hospital (Hospital de Amor, Barretos, Brazil). The DBT system's physical characteristics are shown in Table 1. 
Table 1 - DBT system characteristics ${ }^{4}$.

\begin{tabular}{lc}
\multicolumn{1}{c}{ GE } & Characteristic \\
\hline Detector type & a-Si (Csl:TI) \\
Model & Senographe Essential \\
Projection number & 9 \\
Tube angle span & $25^{\circ}$ \\
Detector angle span & Stationary \\
Tube movement & Step-and-shoot \\
Pixel size & $100 \mu m$ \\
\hline Source: The author (2019). &
\end{tabular}

DBT projections were acquired at a range of radiation doses. We manually fixed the radiographic factors to $29 \mathrm{kVp}$, rhodium target, and filter and then manually set the mAs to: $126,90,72$ and 52 . One acquisition was performed at each configuration, resulting in four sets of 9 projections each. The 126 mAs set was used as input to create the lower dose simulated images. Table 2 shows the dose reduction factors used in this work.

\begin{tabular}{ccc} 
Table 2 - Dose reduction factor for each simulated image. \\
\hline $\begin{array}{c}\text { Input } \\
\text { image (mAs) }\end{array}$ & $\begin{array}{c}\text { Simulated } \\
\text { image (mAs) }\end{array}$ & $\begin{array}{c}\text { Simulated } \\
\text { dose (\%) }\end{array}$ \\
\hline \multirow{2}{*}{126} & 90 & 71 \\
\cline { 2 - 3 } & 72 & 57 \\
\cline { 2 - 3 }
\end{tabular}

Source: The author (2019).

Noise parameters were estimated according to the procedure described in previous work ${ }^{24}$. We evaluated the signal-to-noise ratio (SNR) and the normalized noise power spectrum (NNPS) in both simulated and real images, to measure the performance of the proposed algorithm. The SNR was measured using a sliding window of $64 \times 64$ pixels, and calculated as in Equation 5.

$$
\operatorname{SNR}(i, j)=\frac{\mu(i, j)}{\sigma(i, j)},
$$

where $\mu$ and $\sigma$ represent the local mean and the standard noise deviation from a window centered at $(i, j)$, respectively. For each pair of real and simulated images, an SNR profile was plotted from the chest wall to nipple direction.

Furthermore, the NNPS was estimated in a ROI of size $100 \times 100 \mathrm{~mm}$, at $60 \mathrm{~mm}$ from the chest wall according to Equation 6 and 7. A radial mean was performed in the frequency domain to generate a 1D profile.

$$
\begin{gathered}
N P S=\frac{N s^{2}}{M} \sum_{m=1}^{M}\left|\mathcal{F}\left(I_{m}-S_{m}\right)\right|^{2}, \\
N N P S=\frac{N P S}{L^{2}},
\end{gathered}
$$

where $N$ is the number of pixel in a patch, $s$ is the detector size, $M$ indicates the number of patches taken from the image, $\mathcal{F}$ indicates a Fourier transform, $I_{m}$ and $S_{m}$ are the signal and detrending surface of the patch, respectively, and $L$ is the average value of $I$. As the estimated low frequencies do not represent the true noise behavior, we only show the data above 0.5 $\mathrm{Hz}$.
The simulation error was measured by the average relative absolute error between the SNR maps of the simulated and real images. The NNPS was evaluated in the same way, following Equation 8.

$$
E_{x}=\frac{100 \%}{M} \sum_{m=1}^{M} \frac{\left|X_{m}^{\text {real }}-X_{m}^{\text {simulated }}\right|}{X_{m}^{\text {real }}}
$$

where $X_{m}^{\text {real }}$ and $X_{m}^{\text {simulated }}$ are the real and simulated quantities being evaluated, respectively, and $M$ is the number of samples.

Due to the limited number of realizations, the SNR and NNPS estimates reported strong variations. To minimize such variations, a second-order polynomial surface and an exponential curve were fitted to each SNR map and NNPS profile, respectively, before the errors were estimated, as done in 24 .

Finally, we measured the influence of the correlation kernel in the simulation process. The error between images simulated with and without the kernel was estimated.

\section{Results \& Discussion}

Figure 1 illustrates the SNR profile along the chest wall to nipple direction. The measurements were performed at the central projection at different doses. The graphic shows that the SNR decreases towards the nipple. This is a consequence of the system uniformity calibration flat-fielding.

Figure 2 shows the average relative absolute error between simulated and real images for each projection. The bars represent the standard deviation of the error. The average relative error in SNR between the simulated and real images is below $2.5 \%$ for all projections.

Figure 3 shows the NNPS at the central projection for each simulated dose reduction. Note that the method was capable of accurately simulating the noise properties in the frequency domain. As expected, the aspect of the graphic is not flat due to the noise correlation generated by the image acquisition process.

Figure 4 shows the average relative absolute error in NNPS between simulated and real images, which is below $5.5 \%$ for all projections.

Figure 1 - SNR posterior-anterior profiles of the central projection for simulated and real images at different radiation doses.

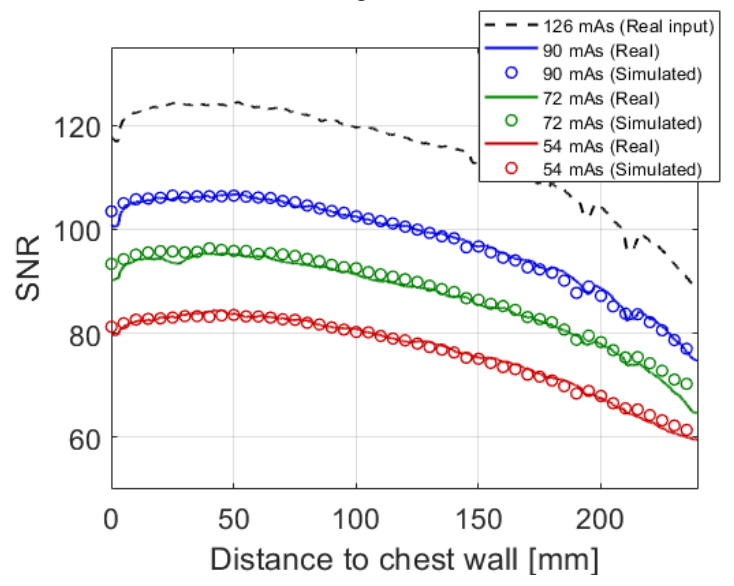


Figure 2 - The average relative absolute error of the SNR maps for simulated and real images at different radiation doses for every projection.

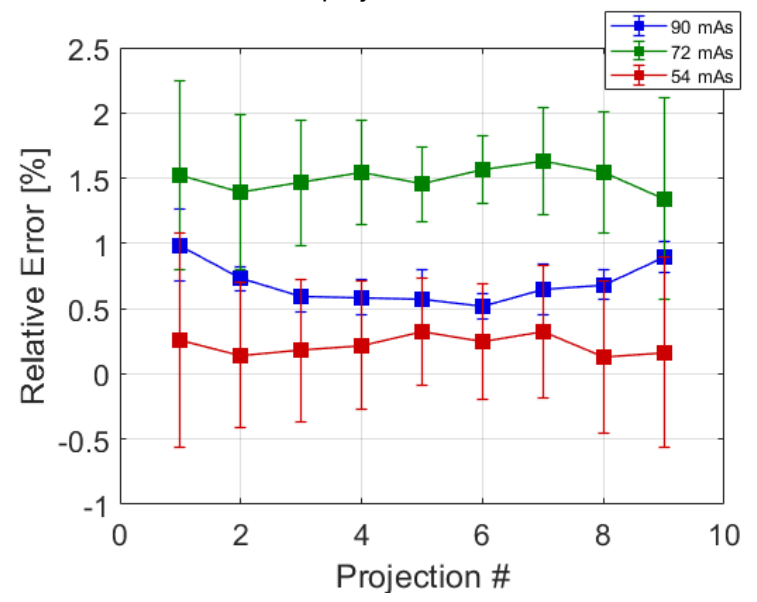

Figure 3 - NNPS profiles of the central projection for simulated and real images at different radiation doses, considering the correlation kernel in the simulation.

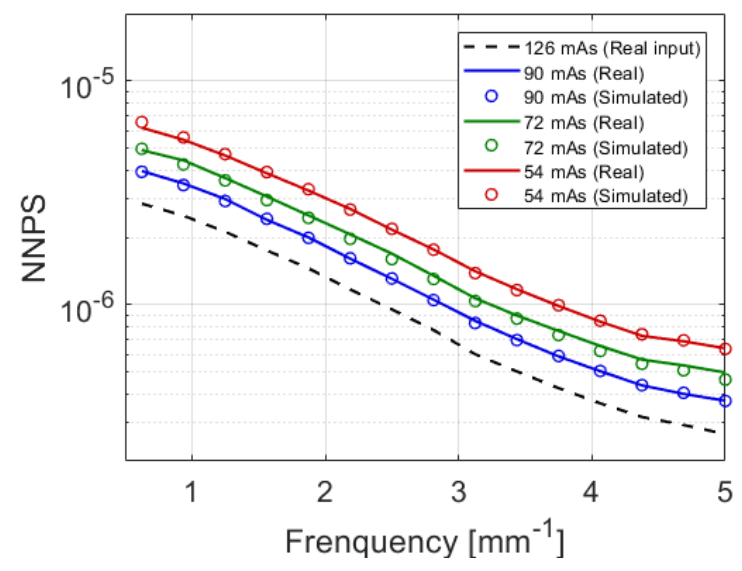

The importance of the correlation kernel in the simulations can be noted in the graphic of Figure 5, which shows the NNPS of the central projection

Figure 4 - The average relative absolute error of NNPS between simulated and real images at different radiation doses for every projection, considering the correlation kernel in the simulation.

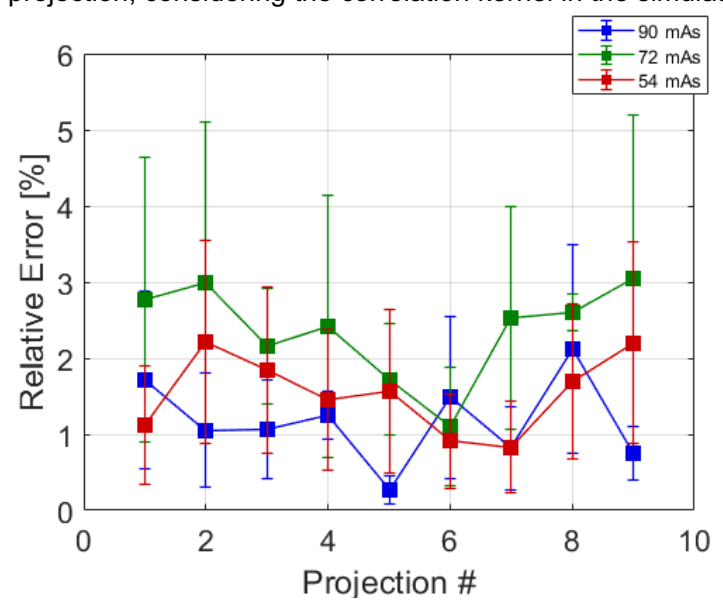

Figure 5 - NNPS average profile of the central projection for simulated and real images at different radiation doses, not considering the correlation kernel in the simulation.

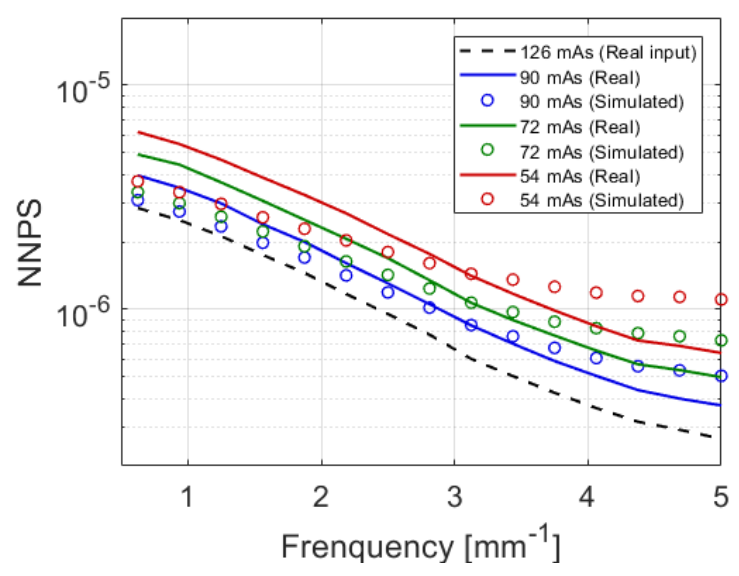

Figure 6 - The average relative absolute error of NNPS between simulated and real images at different radiation doses for every projection, not considering the correlation kernel in the simulation.

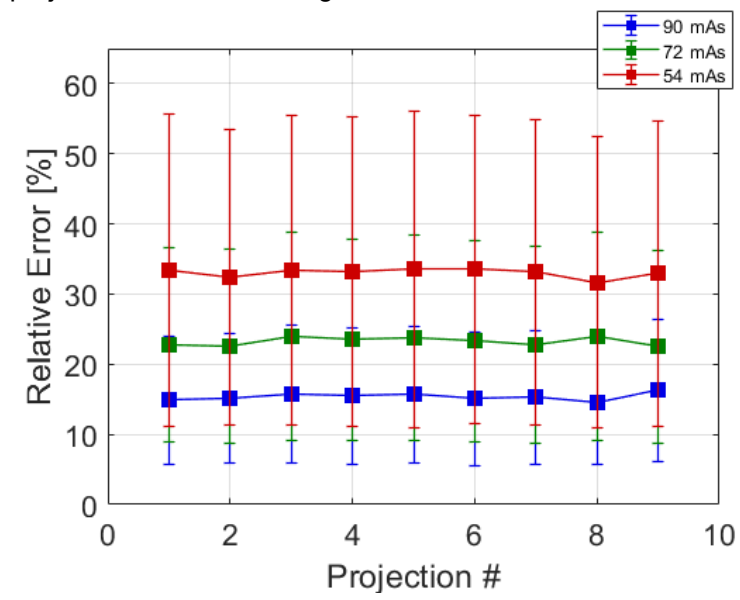

when the correlation kernel is not considered in the simulation, i.e., $K=\delta(0)$. In this case, the simulation resulted in inconsistencies between the simulated and real images. This deviation is more precisely shown in Figure 6, where the relative error in NNPS between the simulated and real image can be up to $55 \%$.

\section{Conclusion}

We evaluated the performance of a previously proposed method to simulate dose reduction using a system that features an a-Si detector. We validated the simulations by means of SNR and NNPS, comparing the results between simulated and real images. The results indicate a maximum error of $2.5 \%$ for the SNR and of 5.5\% for the NNPS, evidencing the accuracy of the simulation process. We also compared images simulated with and without the correlation kernel. The results showed that neglecting noise correlation leads to an incorrect simulation, with errors up to $55 \%$ for the lowest dose considered in this study. Therefore, the proposed method performs a precise simulation in a DBT system featuring (a-Si) detector. 


\section{Acknowledgments}

This work was supported by the São Paulo Research Foundation (FAPESP grants 2016/25750-0 and 2018/19888-5), by the National Council for Scientific and Technological Development (CNPq). The authors would like to thank the Barretos Cancer Hospital for providing the images of the uniform phantom.

\section{References}

1. Inca.gov.br [homepage on the internet]. Brazil: Instituto Nacional de Câncer José Alencar Gomesda Silva (INCA); [Accessed 2019 April 15]. Available from: www.inca.gov.br/.

2. Blanks RG, Wallis MG, Alison R, Kearins O, Jenkins J,Patnick $\mathrm{J}$, et al. Impact of digital mammography on cancer detection and recall rates: 11.3 million screening episodes in the English National Health Service Breast Cancer Screening Program. Radiology. 2018; 290(3): 629-637. https://doi.org/10.1148/radiol.2018181426

3. Saadatmand S, Bretveld R, Siesling S, Tilanus-Linthorst MM. Influence of tumour stage at breast cancer detection on survival in modern times: population based study in 173797 patients. Bmj. 2015; 351:h4901. https://doi.org/10.1136/bmj.h4901

4. Vedantham S, Karellas A, Vijayaraghavan GR, Kopans DB. Digital breast tomosynthesis: state of the art. Radiology.2015;277(3):663-684.

https://doi.org/10.1148/radiol.2015141303

5. Michell M, Batohi B. Role of tomosynthesis in breast imaging going forward. Clinical radiology.2018;73(4):358-371.

6. Samei E, Saunders Jr RS, Baker JA, Delong DM. Digital mammography: effects of reduced radiation dose on diagnostic performance. Radiology. 2007;243(2):396-404. https://doi.org/10.1016/j.crad.2018.01.001

7. Ruschin M, Timberg P, Båth M, Hemdal B, Svahn T, Saunders $\mathrm{RS}$, et al. Dose dependence of mass and microcalcification detection in digital mammography: free response human observer studies. Medical physics.2007;34(2):400-407. https://doi.org/10.1118/1.2405324

8. Saunders RS, Baker JA, Delong DM, Johnson JP, Samei E. Does image quality matter? Impact of resolution and noise on mammographic task performance. Medical physics. 2007;34(10):3971-3981. https://doi.org/10.1118/1.2776253

9. Hadjipanteli A, Elangovan P, Mackenzie A, Looney PT,Wells K, Dance DR, et al. The effect of system geometry and dose on the threshold detectable calcification diameter in 2Dmammography and digital breast tomosynthesis. Physics in

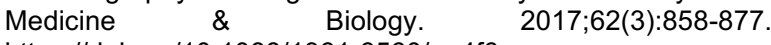
https://doi.org/10.1088/1361-6560/aa4f6e

10. Mackenzie A, Warren LM, Wallis MG, Given-Wilson RM,Cooke $\mathrm{J}$, Dance DR, et al. The relationship between cancer detection in mammography and image quality measurements. Physica Medica. https://doi.org/10.1016/j.ejmp.2016.03.004

11. Timberg $P$, Dustler M, Petersson H, Tingberg A, Zackrisson S. Detection of calcification clusters in digital breast tomosynthesis slices at different dose levels utilizing a SRSAR reconstruction and JAFROC. In: Proceedings of SPIE Medical Imaging 2015: Image Perception, Observer Performance, and Technology Assessment. International Society for Optics and Photonics; 2015; 9416(04). https://doi.org/10.1117/12.2081879

12. Reiser I, Nishikawa R. Task-based assessment of breast tomosynthesis: Effect of acquisition parameters and quantum noise. Medical physics. 2010;37(4):1591-1600. https://doi.org/10.1118/1.3357288

13. Yaffe MJ, Mainprize JG. Risk of radiation-induced breast cancer from mammographic screening. Radiology. 2011;258(1):98-105. https://doi.org/10.1148/radiol.10100655

14. Båth $M$, Håkansson $M$, Tingberg $A$, Månsson LG. Method of simulating dose reduction for digital radiographic systems. Radiation protection dosimetry. 2005;114(1-3):253-259. https://doi.org/10.1093/rpd/nch540

15. Svalkvist $A$, Båth $M$. Simulation of dose reduction in tomosynthesis. Medical physics. 2010;37(1):258-269. https://doi.org/10.1118/1.3273064

16. Mackenzie A, Dance DR, Workman A, Yip M, Wells K, Young $\mathrm{KC}$. Conversion of mammographic images to appear with the noise and sharpness characteristics of a different detector and x-ray system. Medical physics. 2012;39(5):2721-2734. https://doi.org/10.1118/1.4704525

17. Mackenzie A, Dance DR, Diaz O, Young KC. Image simulation and a model of noise power spectra across a range of mammographic beam qualities. Medical physics. 2014;41(12):121901. https://doi.org/10.1118/1.4900819

18. Borges LR, de Oliveira HC, Nunes PF, Bakic PR, Maidment $A D$, Vieira MA. Method for simulating dose reduction in digital mammography using the Anscombe transformation. Medical physics. https://doi.org/10.1118/1.4948502 2016:43(6Part1):2704-2714.

19. Borges LR, Guerrero I, Bakic PR, Foi A, Maidment AD, Vieira MA. Method for simulating dose reduction in digital breast tomosynthesis. IEEE transactions on medical imaging. 2017;36(11):2331-2342.

https://doi.org/10.1109/TMI.2017.2715826

20. Zheng J, Fessler JA, Chan HP. Detector blur and correlated noise modeling for digital breast tomosynthesis reconstruction. IEEE transactions on medical imaging.2018;37(1):116-127. https://doi.org/10.1109/TMI.2017.2732824

21. McEntee MF. Clinical Radiographic Units. In: Russo P, editor. Handbook of X-ray Imaging: Physics and Technology.1st ed. Boca Raton: CRC Press; 2017. p. $518-544$.

22. Azzari L, Borges LR, Foi A. Modeling and Estimation of SignalDependent and Correlated Noise. In: Bertalmío M, editor. Denoising of Photographic Images and Video: Fundamentals, Open Challenges and New Trends. Switzerland: Springer; 2018. p. 13-36.

23. Borges LR, da Costa Vieira MA, Foi A. Unbiased injection of signal-dependent noise in variance stabilized range. IEEE Signal Processing Letters.2016;23(10):1494-1498. https://doi.org/10.1109/LSP.2016.2601689

24. Borges LR, Barufaldi B, Caron RF, Bakic PR, Foi A, Maidment ADA, et al. Technical Note: Noise models for virtual clinical trials of digital breast tomosynthesis. Medical Physics. 2019;46(6): 2683-2689. https://doi.org/10.1002/mp.13534

\section{Contact:}

Autor Correspondente:

Renann de Faria Brandão

Universidade de São Paulo

Av. Trab. São Carlense, 400 - Parque Arnold

Schimidt, São Carlos - SP, 13566-590

E-mail: renannbrandao@usp.br

Rodrigo de Barros Vimeiro

Universidade de São Paulo

Av. Trab. São Carlense, 400 - Parque Arnold

Schimidt, São Carlos - SP, 13566-590

E-mail: rodrigo.vimieiro@usp.br

\section{Lucas Rodrigues Borges}

Universidade de São Paulo

Av. Bandeirantes, 3900 - Vila Monte Alegre, Ribeirão

Preto - SP, 14049-900

E-mail: Lucas.rodrigues.borges@usp.br

\section{Renato França Caron}

Hospital de Câncer de Barretos

R. Antenor Duarte Viléla, 1331 - Dr. Paulo Prata,

Barretos - SP, 14784-400

E-mail: renato.caron@hcancerbarretos.com.br

\section{Marcelo Andrade Costa Vieira}

Universidade de São Paulo

Av. Trab. São Carlense, 400 - Parque Arnold

Schimidt, São Carlos - SP, 13566-590

E-mail:mvieira@sc.usp.br 